\title{
Process Development and Characterization of 2-Aminopyridine Potassium Dihydrogen Orthophosphate (2APKDP) Crystal
}

\author{
D. Sivavishnu ${ }^{1^{*}}$, R. Srineevasan ${ }^{2}$, J. Johnson ${ }^{3}$ \\ ${ }^{1,2,3}$ Department of Physics, Government Arts College, Tiruvannamalai -606 603, Tamil Nadu, India \\ *Corresponding Author: sivavishnup6@rediffmail.com, Tel.: +91-82208-20151
}

Available online at: www.isroset.org

Received: 05/Apr/2019, Accepted: 29/Apr/2019, Online: 30/Jun/2019

\begin{abstract}
A good optical quality bulk size defect free crystal of 2-aminopyridine potassium dihydrogen orthophosphate (2APKDP) was successfully grown from aqueous solution by slow evaporation solution growth technique at room temperature. The presence of functional groups in synthesized compound was identified by FT-IR analysis. Powder XRD pattern of 2APKDP crystal confirms the crystalline nature and $(\mathrm{h} \mathrm{k} \mathrm{l)} \mathrm{values} \mathrm{are} \mathrm{indexed.} \mathrm{Single} \mathrm{crystal} \mathrm{X-ray} \mathrm{diffraction} \mathrm{analysis} \mathrm{shows}$ that the 2APKDP crystal crystallizes in tetragonal crystal system with noncentrosymmetric space group I4. Grown crystals has lower cut off wavelength $290 \mathrm{~nm}$ which is confirmed by UV-visible absorption studies and optical band gap was calculated using UV-vis-NIR spectrum data. The mechanical strength of the grown crystals was tested by Vicker's microhardness tester. The second order nonlinear optical property of the grown sample was analyzed by Kurtz-Perry powder technique. As grown 2APKDP crystal has high SHG efficiency which is 1.2 times that of known KDP. The dielectric constant and dielectric loss of grown 2APKDP crystal has been studied. A laser damage threshold study was carried out for 2APKDP crystal.
\end{abstract}

Keywords - Solution growth; non-centrosymmetric crystal; Band gap; SHG efficiency; LDT.

\section{INTRODUCTION}

Optical materials with many significant achievements have occurred in the field of nonlinear optics because of the development of laser technology and new nonlinear optical materials of both inorganic and organic types [1,2]. Second order nonlinear optical (SONLO) materials are proved to be interesting candidates for number of applications like second harmonic frequency conversion, electro-optic modulation and optical parametric amplification [3, 4]. The organic nonlinear optical materials with aromatic ring have been attracting much attention because of their high nonlinearity [5-7]. Purely inorganic materials typically have excellent mechanical and thermal properties with relatively modest optical nonlinearities because of lack of $\pi$-electron delocalization [8].

Aminopyridine ligand complexes are class of compounds well known for a long time [9]. In recent years metal organic complexes have attracted considerable attention owing to their application in second and third harmonic generation, optical bistability, laser remote sensing, optical data storage, laser driven fusion, medical and spectroscopic image processing, color display and optical communication [1012]. The major limitations in organic nonlinear optical (NLO) devices are low laser damage threshold, low optical transparency, and lack of the bulk size crystals. The inorganic NLO crystals possess relatively modest optical nonlinearity due to the lack of extended $\pi$-electron delocalization.

In semiorganics, polarizable organic molecules are stoichiometrically bound within an inorganic host; the NLO properties of semiorganic complex products of thiourea have attracted great interest because these metal-organic complexes combine the high optical nonlinearity and chemical flexibility of organics with the physical simplicity of inorganic [13, 14]. When an organic material mixed with amino acid, NLO property was found to be increased due to the zwitterionic nature associated with enhanced transparency range[15,16]. KDP crystal plays an important role in the field of NLO and is used in quantitative $\mathrm{x}$-ray analysis [17].

Amino acid contains a deprotonated carboxylic acid group $\left(\mathrm{COO}^{-}\right)$and protonated amino group $\left(\mathrm{NH}_{3}^{+}\right)$. This dipolar nature exhibits peculiar physical and chemical properties in amino acids, thus making them ideal candidate for NLO applications [18-20].

In recent years, research in engineering of 2-Aminopyridine complex crystal is very interesting for optical applications. 
The crystal structure of 2-aminopyridine is monoclinic and it has been reported earlier [21]. 2-Aminopyridine is used in the synthesis of pharmaceuticals especially for antihistamines, antiflammatories and other drugs. It is also used as a monomer for polymerization. At present, the investigation on 2-Aminopyridine metal complex is of great interest for optoelectronic applications [22].

One of the obvious requirements for a non linear optical crystal is that it should have excellent optical quality. Potassium dihydrogen orthophosphate, $\mathrm{KH} 2 \mathrm{PO} 4$ (KDP) is a good nonlinear crystal material due to its interesting electrical and optical properties, structural phase transitions and its easy crystallization [23]. The study of KDP is of great interest because of its unique non linear optical properties and vast applications in the field of high power laser systems. Potassium dihydrogen orthophosphate is a model system for a non linear optical device application. Large single crystal of KDP is used for frequency conversion and as parts of large aperture optical switches in the laser fusion systems [24].

In this present research we report on synthesis, growth and physicochemical properties of 2-Aminopyridine Potassium Di-hydrogen Orthophosphate crystal. Basically the 2-aminopyridine crystal crystallizes in centrosymmetric crystal system, but in addition of potassium dihydrogen orthophosphate the crystal crystallizes in noncentrosymmetric crystal system. The 2-Aminopyridine Potassium Di-hydrogen Orthophosphate crystals have many applications in optoelectronics.

\section{EXPERIMENTAL PROCEDURE}

\section{A. Material Synthesis of 2APKDP}

An analytical reagent grade of 2-aminopyridine and potassium dihydrogen orthophosphate was synthesized in equimolar ratio 1:1 using double distilled water as a solvent by using slow evaporation technique at room temperature. The chemical reaction of synthesized compound was given below and the molecular scheme of 2APKDP was shown in Figure 1.

$$
\mathrm{C}_{5} \mathrm{H}_{6} \mathrm{~N}_{2}+\mathrm{KH}_{2} \mathrm{PO}_{4} \rightarrow \mathrm{C}_{5} \mathrm{H}_{6} \mathrm{~N}_{2} \mathrm{KH}_{2} \mathrm{PO}_{4}
$$

2-aminopyridine + Potassium dihydrogen orthophosphate $\rightarrow$ 2APKDP

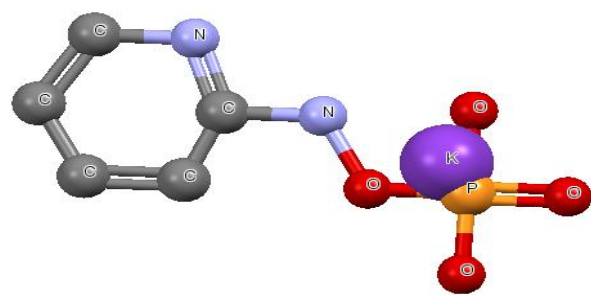

Figure 1. Molecular scheme of 2APKDP

\section{B. Solubility of 2APKDP}

The purity of the synthesized salt was further improved by successive recrystallization process. The solubility of the synthesized salt was carried out at various temperature from $30{ }^{\circ} \mathrm{C}$ to $60{ }^{\circ} \mathrm{C}$ in $5{ }^{\circ} \mathrm{C}$ intervals by dissolving the solute in de-ionized water in an airtight container. After attaining saturation, the equilibrium concentration of the solute was analyzed gravimetrically. The same procedure was repeated and the solubility curve for different temperatures was drawn. Figure 2 shows the solubility curve for 2APKDP in aqueous solution.

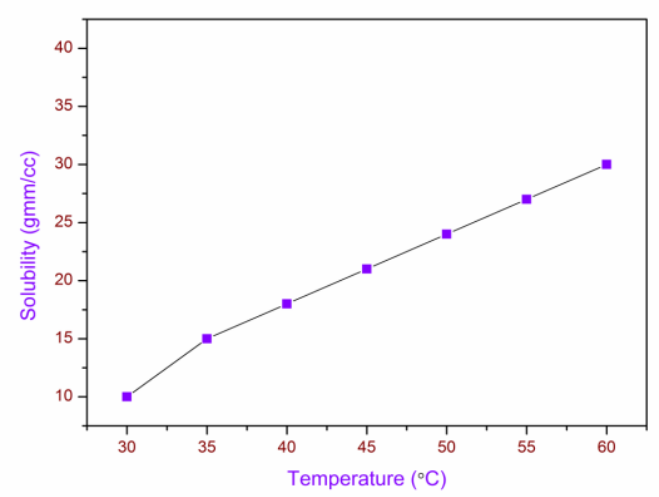

Figure 2. Solubility curve of 2APKDP

\section{B. Crystal Growth of 2APKDP}

The synthesized solution of 2APKDP was stirred for 4 hours continuously using magnetic stirrer to ensure homogeneous mixing of solutions. High degree of purification of synthesized salt was achieved by successive recrystallization process. The saturated solution was filtered two times with micron pore size filter paper. This synthesized clear solution was poured into a beaker and covered with pores paper, and housed for slow evaporation of the solvent. After 124 days the solvent was evaporated and good quality 2APKDP crystals of size $53 \mathrm{~mm}$ x $38 \mathrm{~mm}$ x $10 \mathrm{~mm}$ were harvested. The grown crystal was optically transparent. As-grown crystal of 2APKDP is shown in Figure. 3 and Morphology of $2 A P K D P$ crystal is shown in Figure 4.

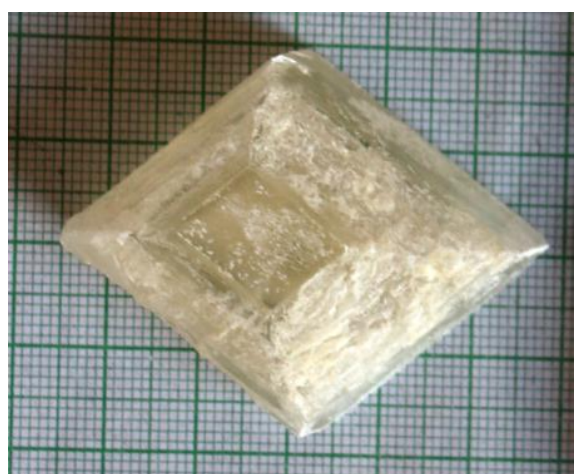

Figure 3. Photography of as grown crystal of 2APKDP 


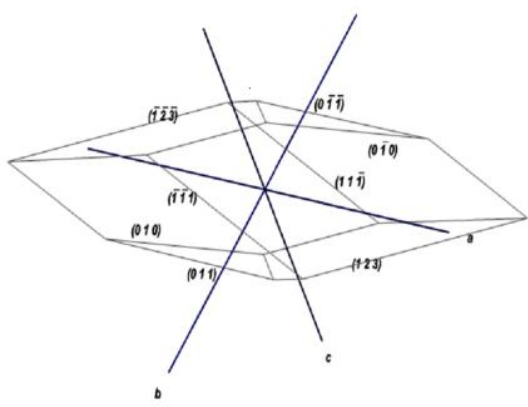

Figure 4. Morphology of 2APKDP Crystal

\section{CHARACTERIZATION TECHNIQUES}

\section{A. Fourier Transform Infrared analysis}

In order to analyze the synthesized compound qualitatively for the presence of functional groups in the molecule, the FTIR spectrum is recorded between $500-4000 \mathrm{~cm}^{-1}$ using $\mathrm{KBr}$ pellet technique by Brukker IFS 66V Fourier transform infrared spectrometer. The spectrum obtained is shown in Figure 5 and the band assignments are shown in table 1.

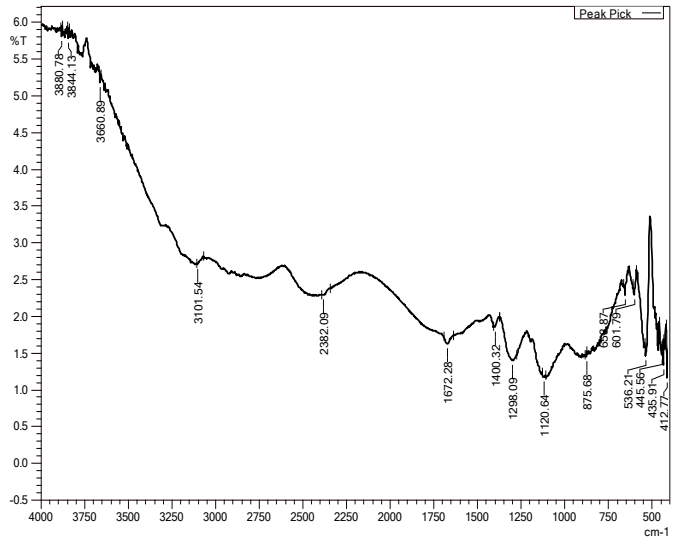

Figure 5. FTIR spectrum of 2APKDP crystal

Table 1. Assignments of IR band frequencies $\left(\mathrm{cm}^{-1}\right)$ for 2APKDP crystal

\begin{tabular}{|l|l|}
\hline $\begin{array}{c}\text { Wave number } \\
\mathbf{c m}^{-1}\end{array}$ & \multicolumn{1}{|c|}{ Assignments } \\
\hline 3880 & O-H stretching \\
\hline 3844 & O-H stretching \\
\hline 3660 & O-H bending \\
\hline 3101 & $\mathrm{NH}_{3}{ }^{+}$Stretching \\
\hline 2382 & $\mathrm{NH}^{-1}$ stretching \\
\hline 1672 & P-O-H stretching \\
\hline 1400 & O-H stretching \\
\hline
\end{tabular}

\begin{tabular}{|c|l|}
\hline 1298 & $\mathrm{P}=\mathrm{O}$ stretching \\
\hline 1120 & P-O stretching \\
\hline 875 & P-O-H stretching \\
\hline 653,601 & COO $^{-}$bending \\
\hline 536 & P-OH deformation / K-O stretching \\
\hline 445 & Presence of Metal ion \\
\hline 435 & Presence of Metal ion \\
\hline
\end{tabular}

\section{Powder X-ray diffraction analysis}

The crushed fine powder sample of 2APKDP was subjected to powder X-ray diffraction analysis by using BRUCKER, Germany (model D8 Advance) X-ray diffractometer with cuk $_{\text {alpha }}$ (wavelength $=1.5405 \mathrm{~A}^{0}$ ) radiation. The powder sample was scanned over the range $10-80^{\circ}$ at a scan rate of $1^{\circ} /$ min. The well defined Bragg peaks are obtained at specific $2 \theta$ an angle which reveals that the grown crystal has good quality and high crystalline nature. The Powder XRD patterns 2APKDP crystal is obtained and (h k l) values are indexed using INDX software. The powder XRD pattern of grown crystal 2APKDP is shown in Figure 6.

\section{Single crystal X-ray diffraction analysis}

As grown crystal was subjected to $\mathrm{X}$-ray diffraction analysis using ENRAF NONIUS CAD 4 diffractometer with $\mathrm{MoK} \alpha$ radiation $\lambda=0.71073 \AA$. The calculated unit cell parameters of 2APKDP crystal are a $=7.53 \AA, b=7.53 \AA, c=7.02 \AA$ and volume $\mathrm{V}=398 \AA^{3}$, which shows that the grown crystal 2APKDP belongs to tetragonal crystal system with noncentrosymmetric space group I4.

2-aminopyridine crystallizes in monoclinic crystal system with centrosymmetric but incorporation of potassium dihydrogen orthophosphate (KDP) the 2APKDP crystal crystallizes in non-centrosymmetric shown in Table 2.

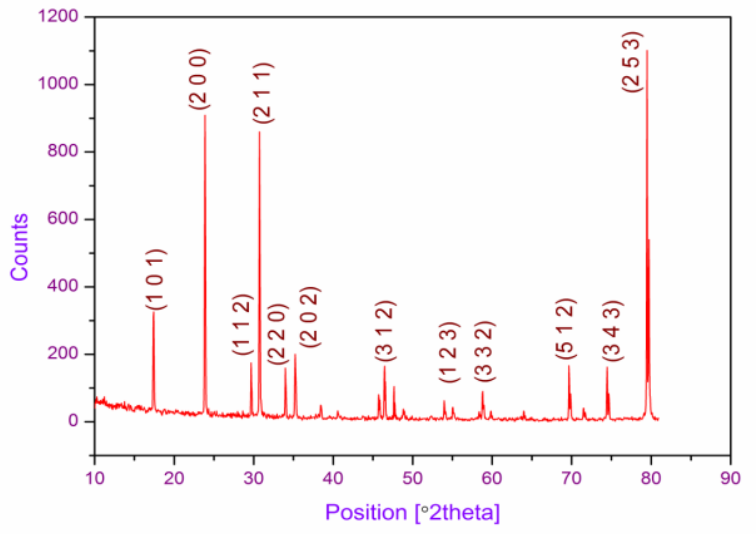

Figure 6. Powder XRD pattern of 2APKDP crystal 
Table 2. Crystal system of 2AP and 2APKDP crystal

\begin{tabular}{|c|c|c|}
\hline & 2AP [21] & 2APKDP \\
\hline $\mathbf{a} \AA$ & 11.70 & 7.53 \\
\hline $\mathbf{b} \AA$ & 5.67 & 7.53 \\
\hline $\mathbf{c} \AA$ & 7.59 & 7.02 \\
\hline $\begin{array}{c}\text { Volume } \\
\AA^{\mathbf{3}}\end{array}$ & 503 & 398 \\
\hline Structure & Monoclinic & Tetragonal \\
\hline Space goup & $\mathrm{P} 2_{1} / \mathrm{c}$ & I4 \\
\hline
\end{tabular}

\section{*Present work}

\section{E. UV-vis-NIR spectroscopy study}

An optically polished 2APKDP single crystal was subjected to UV-vis-NIR spectrometer analysis using SHIMADZU UV-160 Spectrometer to find the transmission and absorption range about the suitability of this grown crystal for optical applications. The UV absorption spectrum was scanned in the range of $200 \mathrm{~nm}$ to $800 \mathrm{~nm}$ for 2APKDP crystal shown in Figure 7. A strong absorption and the UV cut off wavelength lies at $290 \mathrm{~nm}$ for 2APKDP crystal, and it reveals the good optical quality. High transmission in the entire visible region proves the suitability of grown crystal as UV tunable laser and in second harmonic generation (SHG) device applications.

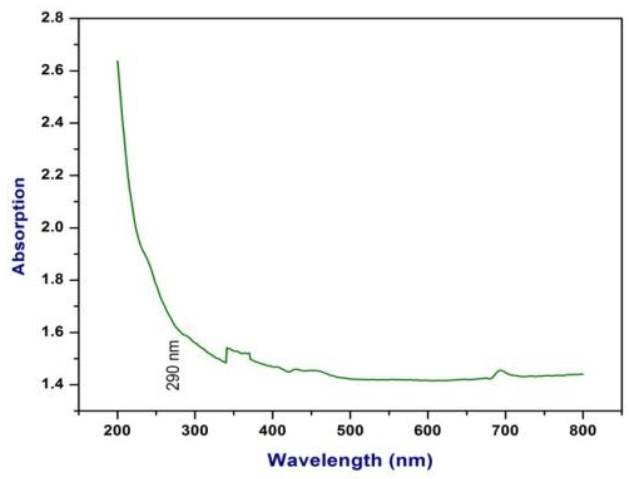

Figure 7. Optical absorption spectrum of 2APKDP

\section{F. Optical band gap of 2APKDP crystal}

The dependence of optical absorption coefficient on photon energy helps one to study the band structure and the type of transition of electrons [25]. The optical absorption coefficient $(\alpha)$ was calculated from transmittance using the following relation.

$$
\alpha=\frac{(2.3026 \log (1 / T))}{t}
$$

Where $\mathrm{T}$ is the transmittance and $\mathrm{d}$ is the thickness of the crystal. As a direct band gap material, the crystal under study has an absorption coefficient $(\alpha)$ obeying the following relation for high photon energies (hv).

$$
\alpha h v=\mathrm{A}\left(\mathrm{h} v-\mathrm{E}_{\mathrm{g}}\right)^{1 / 2}
$$

Where Eg is the optical band gap of the crystal and A is a constant. The plot of variation of $(\alpha . h v)^{2}$ versus $h v$ is shown in Figure 8 for 2APKDP crystal. Optical band gap was evaluated by extrapolation of the linear part [26,27]. The band gap (Eg) is found to be $4.64 \mathrm{eV}$ for 2APKDP crystal. As a consequence of wide band gap, the grown crystal has large transmittance in the visible region [28]. The Tauc's gap is often used to characterize practical optical properties of materials.

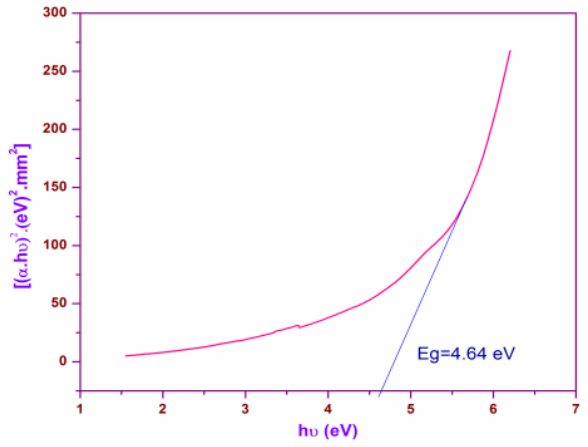

Figure 8. Tauc's plot of 2APKDP crystal

\section{G. Nonlinear optical study}

A Q-switched Nd: YAG laser emitting $1.06 \mu \mathrm{m}$ with power density up to $1 \mathrm{GW} / \mathrm{cm}^{2}$ was used as a source of illuminating the powder sample of 2APKDP for calculating SHG efficiency. The sample was prepared by sandwiching the graded crystalline powder with average particle size of about $90 \mu \mathrm{m}$ between two glass slides using copper spices of 0.4 $\mathrm{mm}$ thickness. A laser was produced a continuous laser pulses repetition rate of $10 \mathrm{~Hz}$. The experimental setup uses a mirror and 50/50 beam splitter. Here well known NLO crystal KDP is taken as a reference material.

The fundamental beam was splitted into two beams by the beam splitter (BS); one of them was used to illuminate the powder under study and the other constituted the reference beam of power P $\omega$. Half-wave plate $(\mathrm{HW})$ placed between two parallel polarizers (P) and was used to pump the beam power. The input power was fixed at $0.701 \mathrm{~J}$ and the output power was measured as $10.72 \mathrm{~mJ}$, which was compared to output $8.91 \mathrm{~mJ}$ of standard KDP. The diffusion of bright green radiation of wave length $\lambda=532 \mathrm{~nm}\left(\mathrm{P}_{2} \omega\right)$ by the sample confirms second harmonic generation (SHG). The powder SHG efficiency of 2APKDP crystal was about 1.2 times of KDP. The good second harmonic generation efficiency indicates that the grown crystals can be used as a suitable material for non-linear optical devices

\section{H. Vickers Microhardness study}

The Vickers hardness indentations were made on the cut and polished grown crystal of $2 \mathrm{APKDP}$ at room temperature with load range of 25, 50 and $100 \mathrm{~g}$ using Vickers hardness 
tester fitted with Vickers diamond indenter and attached to an incident light microscope.. The Vickers micro hardness number is evaluated using the formula $\mathrm{Hv}=1.854 \mathrm{P} / \mathrm{d}^{2}$ $\left(\mathrm{kg} / \mathrm{mm}^{2}\right)$, Where $\mathrm{Hv}$ is the Vickers hardness number in $\left(\mathrm{kg} / \mathrm{mm}^{2}\right), P$ is the applied load in $\mathrm{g}$ and $\mathrm{d}$ is the diagonal length of the indentation impression in $\mu \mathrm{m}$ and 1.854 is a constant of a geometrical factor for the diamond pyramid. From Figure 9, it is observed that initially the hardness increases with increase of load. At the low loads the indenter pierces only top surface layers resulting in increase of hardness and thereafter becomes load independent. Beyond the load of $100 \mathrm{~g}$, a significant crack developed around the indentation mark, which may be due to the release of internal stresses generated at the corners of the indentation. The initial increase in microhardness (Hv) with increasing load is in agreement with the reverse indentation size effect (RISE).

By Meyer's law the size of indentation and the load are related as

$$
\mathrm{P}=\mathrm{k}_{1} \mathrm{~d}^{\mathrm{n}}
$$

Where $\mathrm{k}_{1}$ is the material constant and $\mathrm{n}$ is Meyer's index.

$$
\log \mathrm{P}=\log \mathrm{k}_{1}+\mathrm{n} \log \mathrm{d}
$$

The plot of $\log \mathrm{P}$ vs. Log d fitting data before cracking gives a straight line, which are in good agreement with Meyer's law (Figure 10). The slope of the graph gives the value of ' $n$ '. The slope of the linear fit is the Meyer's index, and observed to be $\mathrm{n}=0.32$. According to Onitsch and Hanneman [29], ' $n$ ' should lie below 1.6 for comparatively hard materials, whereas it is above 1.6 for softer ones. Thus 2APKDP crystal belongs to hard materials category.

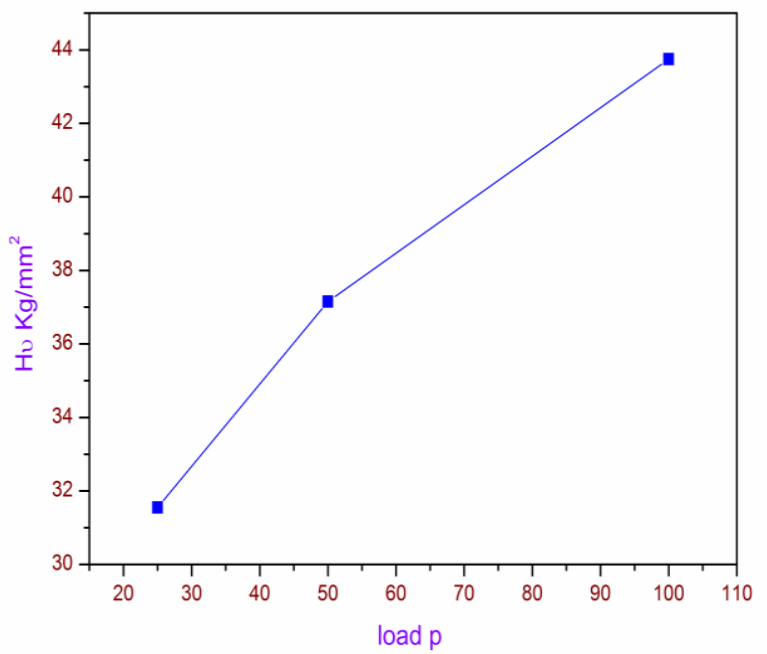

Figure 9. Variation of load p versus Hv of 2APKDP crystal

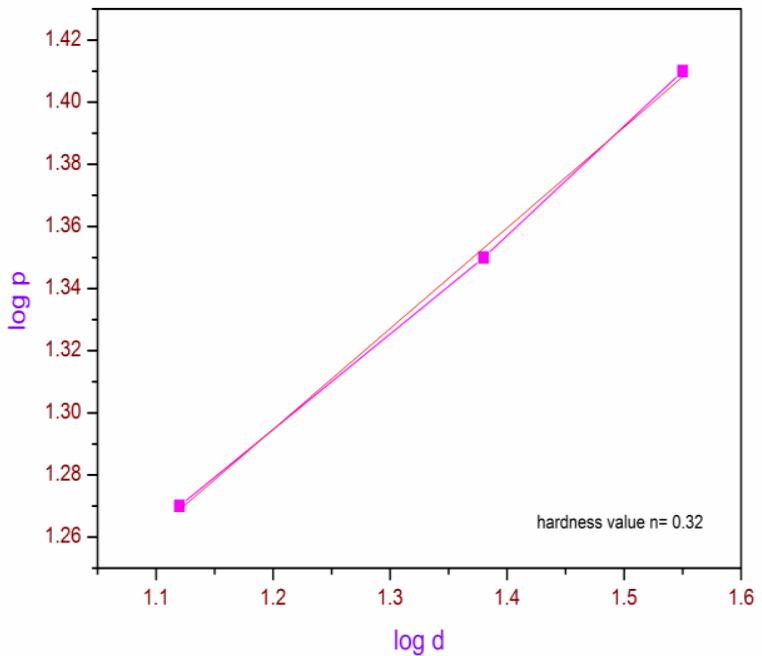

Figure 10. Plot of $\log d$ versus $\log p$ of $2 A P K D P$ crystal

\section{Dielectric studies}

Dielectric study was most important to know the electrooptic coefficient of the crystals and hence the dielectric properties for technical applications [30]. Optically good quality 2APKDP crystal was selected for dielectric measurements using HIOKI 3532-50 LCR HITESTER. The selected samples were cut using a diamond saw and polished using paraffin oil. Silver paint was applied on the both faces to make a capacitor with the crystal as dielectric material. Both dielectric constant and dielectric loss were measured for 2APKDP crystal. Crystals were carefully selected with high transparency and defect-free surface (without any pit or crack or scratch on the surface). As the frequency increased, both the dielectric constant and the dielectric loss values were found to be decreased exponentially which is shown in Figure 11. . The dielectric constant $\left(\varepsilon_{\mathrm{r}}\right)$ at low frequencies depends on the excitation of bound electrons, lattice vibrations, dipole orientation and space-charge polarization (atomic or electronic). At very low frequencies all four contributions may be active, so it has a high value. The lower value of the dielectric constant at higher frequencies explains the higher SHG conversion efficiency of the asgrown crystal and this is in agreement with the Miller rule [31].

The variation of dielectric loss vs. log frequency is shown in Figure 12. From the graph, it is found that the dielectric loss decreases with increase in frequencies. The value of dielectric loss is high at lower frequencies and it is low at higher frequency region. The low values of dielectric loss imply that the sample possesses enhanced, optical quality with lesser defects and this parameter indicates that the material can be useful for NLO applications [32]. 


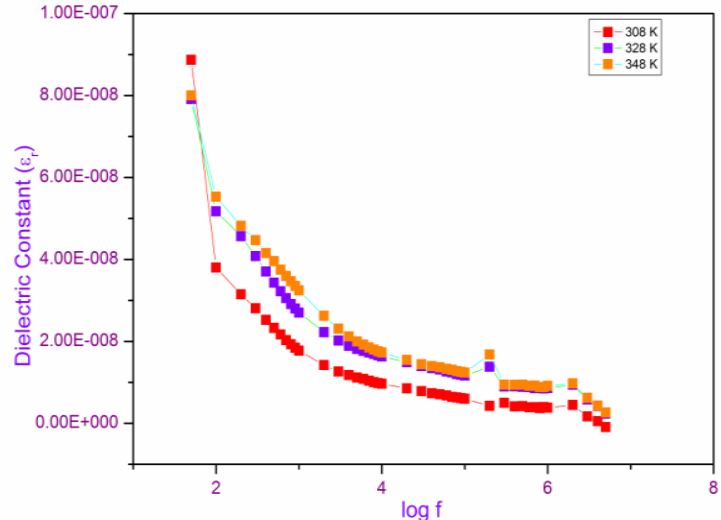

Figure 11. Variation of $\log f$ versus Dielectric constant $\left(\varepsilon_{\mathbf{r}}\right)$

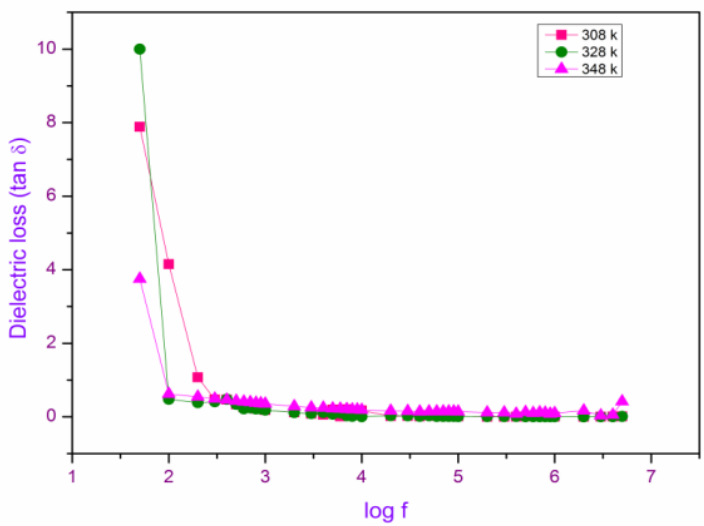

Figure 12. Variation of $\log f$ versus Dielectric loss $(\tan \delta)$ J. Laser damage threshold study

The laser damage threshold of an optical crystal is an important factor affecting its applications. If the material has a low laser damage threshold it severely limits its applications, even though it has many excellent properties like high optical transmittance and high SHG efficiency [33-35]. The present study is of great interest to find out the influence of combining an organic 2-aminopyridine with potassium di-hydrogen orthophosphate and find out the modification in the laser induced damage and thereby to prescribe the maximum permissible laser power for the newly formed semiorganic crystals. A Q-switched high energy Nd:YAG was used to generate pulses at $1064 \mathrm{~nm}$ fundamental radiation at a frequency of $10 \mathrm{~Hz}$ and pulse duration of $6 \mathrm{~ns}$. The laser beam of diameter 1 $\mathrm{mm}$ was focused on the $2 \mathrm{~mm}$ of $2 \mathrm{APKDP}$ crystal. The sample was placed at the focus of a Bi-convex lens of focal length $20 \mathrm{~cm}$. The pulse energy of each shot was measured using the combination of phototube and oscilloscope.

The measured multiple shot laser damage threshold value is $74 \mathrm{~mJ}$ for $1064 \mathrm{~nm}$ wavelength of Quantum Nd:YAG laser radiation.

\section{CONCLUSION}

A new NLO material 2APKDP has been synthesized and crystal was grown by slow evaporation method at room temperature. The presences of functional groups have been identified from FT-IR analysis. The crystalline nature of the grown 2APKDP crystal was confirmed by well defined sharp peaks from powder X-ray diffraction analysis. The lattice parameter values have been evaluated by single crystal XRD analysis. From the XRD analysis, we confirm that the crystal 2APKDP belongs to tetragonal crystal system with non-centrosymmetric space group I4. UV-visible-NIR analysis was carried out to determine the lower cut off wavelength at $290 \mathrm{~nm}$ and optical band gap $\mathrm{Eg}=4.64 \mathrm{eV}$ was determined from UV-vis-NIR spectrum data. The SHG behavior was confirmed from the emission of bright green radiation $(532 \mathrm{~nm})$ and the SHG efficiency was found to be 1.2 times greater than that of KDP, so it is a good NLO material for several NLO applications. A Vickers hardness test was carried out and the hardness number was found to be 0.32 confirm that the 2 APKDP crystal belongs to hard category. The dielectric studies of 2APKDP crystal establish as the frequency increased, both the dielectric constant and dielectric loss values were found to be decreased exponentially. Laser damage threshold value was found to be $74 \mathrm{~mJ}$, which evident that the 2APKDP material has more optical applications.

\section{ACKNOWLEDGEMENT}

The authors would like to thank Professor Dr. R. Jayavel, Director, Centre for Nanotechnology, Anna University, Chennai. Dr. G. Elango, PG and Research Department of Chemistry, Government Arts College,Tiruvannamalai. Archbishop Casimir Instrumentation Center (ACIC), St. Joseph College (Autonomous), Tiruchirappalli and B. S. Abdur Rahman University, Vandalur, Chennai, for providing the instrument facility for characterization.

\section{REFERENCES}

[1]. J.F. Nicoud, R.J. Twieg, Nonlinear optical properties of organic molecules and crystals, Quantum Electronics. Principles and Applications, Academic Press. Inc, 1b, pp. 227-296, 1987.

[2]. Sunil Verma, M.K. Singh, V.K. Wadhawan, C.H. Suresh, Pramana, Growth morphology of zinc tris(thiourea) sulphate, J. Phys. Vol. 54, Issue 16,pp. 879, 2000.

[3]. D.S. Chemla, J. Zyss, Nonlinear optical properties of organic molecules and crystals, Quantum Electronics. Principles and Applications, Academic Press. Inc, pp. 23-191, 1987.

[4]. Ledourx, J. Badan, J. Zyss, A. Migus, D. Hulin, J. Etchepare, G. Grillon, A. Antonetti, Generation of high-peak-power tunable infrared femtosecond pulses in an organic crystal: application to time resolution of weak infrared signals, J. Opt. Soc. Am. B4 , pp. 987997, 1987.

[5]. S. Boomadevi, H.P. Mittal, R. Dhansekaran, Synthesis, Crystal Growth and Characterization of 3-Methyl 4-Nitropyridine 1-Oxide (POM) Single Crystals, J. Cryst. Growth, Vol. 261, pp. 55-62, 2004.

[6]. Thangaraj,M., Ravi, G., Sabari Girisun,T.C., Ethylenediaminium di(2-nitrophenolate) single crystals as materials for optical second harmonic generation. Phys B : Condensed Mat. Vol. 449, pp. 209213, 2014.

[7]. Ashwell, G. J., Jefferies, G., Hamilton, D. G., Lynch, D. E., Roberts, M. P. S., Bahra, G. S., Brown, C. R., Strong second-harmonic generation from centrosymmetric dyes. Nature, Vol. 375, pp. 375 385, 1995.

[8]. M.D. Aggarwal, J. Choi, W.S. Wang, K. Bhat, R.B. Lal, A.D. Shields, B.C. Penn, D.V. Frazier, Solution growth of a novel nonlinear optical material: L-histidine tetrafluroborate, J. Cryst. Growth, Vol. 204, pp. 179-182, 1999.

[9]. G.Xing, M.Jiang, Z.Shao, D.Xu, Chin, Bis(thiourea)cadmium chloride (BTCC) a novel nonlinear optical crystal of organometallic complex, J. Lasers, Vol. 14, pp. 302-308, 1997. 
[10]. R. Srineevasan and R. Rajasekaran, "Growth and optical studies of 2-aminopyridine bis thiourea zinc sulphate (2-APTZS) single crystals for NLO applications", J. Mol. Struct, Vol.1048, pp. 238243, 2013.

[11]. Santhanu Bhattucharya, Parthasarathi, T.N. Guru Row, Hydrogenbond-directed self-assembly of D-(+)-dibenzoyltartaric acid and 4aminopyridine: optical nonlinearities and stoichiometry-dependent novel structural features, Chem. matter. Vol. 6, pp. 531, 1994.

[12]. T. Kumar, S. Janarthanan, S. Pandi, M. Raj, K. and D. Anand, "Synthesis, Growth and Characterization of 4-Benzeneazoaniline Single Crystal," Journal of Minerals and Materials Characterization and Engineering, Vol. 9 No. 11, pp. 961-972, 2010.

[13]. F. Serpaggi, G. Ferey, Hybrid open frameworks (MIL-n). Part 4 Synthesis and crystal structure of MIL-8, a series of lanthanide glutarates with an open framework, $\left[\mathrm{Ln}\left(\mathrm{H}_{2} \mathrm{O}\right)\right]_{2}\left[\mathrm{O}_{2} \mathrm{C}\left(\mathrm{CH}_{2}\right)_{3} \mathrm{CO}_{2}\right]_{3} \cdot 4 \mathrm{H}_{2} \mathrm{O}$, J. Mater. Chem. Vol. 8, pp. 2737-2741, 1998

[14]. G. Xing, M. Jilang, Z. Shao, D. Xu, Chin. FT-IR, photoacoustic and micro-Raman spectra of the dodecacarbonyltriruthenium (O) complexes Ru3 (13CO) 12 and Ru3 (CO) 12, J. Lasers, Vol. 14, pp. 302-308, 1987.

[15]. S. Velsko, Laser Program Annual Report, Lawrence Livermore National Laboratory, Livermore, CA, 1990.

[16]. J. William(Ed). Non Linear Optical Properties of organic and polymeteric Materials, Am. Chem. Soc. Symp. Series. Vol.233, American Chemical Society, Washington, DC, 1983.

[17]. D.S. Chemil, J. Zyss(Eds.), Non Linear Optical Properties of organic molecules and Crystals, Academic Press. New York, 1987(chapter1 and 2).

[18]. J.F. Nicoud, R.J. Twieg, in:D.S. Chemia, J. Zyss(Eds.), Linear Optical Properties of organic molecules and Crystals, Academic Press. London,. P-227, 1987.

[19]. B.A. Fuchs, C. Ksyn, S.P. Velsko, Diamond turning of L-arginine phosphate, a new organic nonlinear crystal, Appl. Opt. Vol. 28, pp. 4465-4472, 1989.

[20]. S.B. Monaco, L.E. Davis, S.P. Velsko, F.T. wang, D. Eimerl, A Zalkin, Synthesis and characterization of chemical analogs of Larginine phosphate, J. Cryst. Growth, Vol. 85, pp. 252-255, 1987.

[21]. By Ming Chao, Ellory Schempp, Robert D. Rosenstein, 2Aminopyridine, Acta. Cryst, B 31, pp. 2922, 1975.

[22]. Arthur E. Landers, David J. Phillips, Metal complexes with 2 aminopyridine $\mathrm{N}$-oxide, including $\mathrm{N}$-oxide-bridged complexes of cobalt(II), nickel(II) and copper(II). Further studies on related pyridine N-oxide complexes, Inorganica Chimica Acta, Vol. 74, pp. 43-53, 1983.

[23]. Ravi G., Haja Hameed A.S. and Ramasamy P. 'Effect of temperature and deuterium concentration on the growth of deuterated potassium dihydrogen phosphate (DKDP) single crystals,' J. Crystal Growth, Vol. 207, pp. 319-324, 1999.

[24]. Robert R., Justin Raj C., Krishnan S., Jerome Das S., 'Growth, theoretical and optical studies on potassium dihydrogen phosphate (KDP) single crystals by modified Sankaranarayanan-Ramasamy (mSR) method'vPhysica B: Condensed Matter, Vol. 405( 1), pp. 2024, 2010.

[25]. R. Robert, C. Justin Raj, S. Jerome Das, Growth and characterization of pure and doped L-Lysine monohydrochloride dihydrate (LLMHCl) nonlinear optical single crystal, Curr. Appl. Phys. Vol. 10, pp. 670-675, 1999.

[26]. V. Vasudevan, R. Ramesh Babu, G. Bhagavannarayana, K. Ramamurth, Effect of. metal and aminoacid dopants on the growth and properties of 1-lysine. monohydrochloride dihydrate single crystal, Mater. Chem. Phys. Vol. 124, pp. 681-688, 2010.

[27]. Eya D D O, Ekpunobi A J, Okeke C E, Influence of thermal annealing on the optical properties of tin oxide thin flims prepared by chemical bath deposition technique, Acad. Open Internet. J. 17 (2006).

[28]. Kumar K, Ramamoorthy K, Koinkar P M, Chandramohan R, Sankaranarayanan K, A novel in situ synthesis and growth of ZnAl2O4 thin films, J.Cryst. Growth, Vol. 289, pp. 405-407, 2006.
[29]. Onitsech, E.M., The present status of testing the hardness of materials. Mikroskopie, Vol. 95, pp. 12-14, 1956.

[30]. C.P. Smyth, in: Dielectric Behaviour and Structure, McGraw-Hill, New York, p. 132, 1965

[31]. B.W. Betterman, H. Cole, Dynamical Diffraction of X Rays by Perfect Crystals, Rev. Mod. Phys, Vol. 36 pp. 681, 1964.

[32]. Manivannan, S., Dhanuskodi, S., Synthesis, growth, structural, optical, and thermal properties of a new semiorganic crystal: 4dimethylamino pyridinium dihydrogen phosphate. Crystal growth and design, Vol. 4 pp. 845-850, 2004.

[33]. N. Vijayan, G. Bhagavannarayana, K.R. Ramesh, R. Gopalakrisnan, K.K. Maurya, P. Ramasamy, Compositional dependence of cationic displacements in lithium niobate and lithium tantalate crystals, Cryst. Growth Res. Vol. 6, pp. 1542-1546, 2006.

[34]. S. Manivannan, S. Dhanuskodi, S.K. Tiwari, Laser induced surface damage, thermal transport and microhardness studies on certain organic and semiorganic nonlinear optical crystals, J. Philip, J. Pure Appl. Phys. Vol. B 90, pp. 489-496, 2008.

[35]. H. Nagatani, W.R. Bosenberg, L.K. Cheng, C.L. Tang, Laser-induced damage in beta-barium metaborate, Appl. Phys. Lett. Vol. 53, pp. 2587-2589, 1988.

\section{AUTHORS PROFILE}

Mr. D. SIVAVISHNU is a Ph.D., Research Scholar under the guidance of Dr. R. SRINEEVASAN M.Sc., M. Ed., M. Phil., Ph. D., in PG \& Research Department of Physics, Government Arts College, Tiruvannamalai - 606 603, Tamilnadu, India. He completed a student project in TNSCST and got a best project and presentation award in M. Sc., degree and also completed M. Phil., degree in first class with distinction. He has published more than 10 research articles in a Peer reviewed journal and also participated and presented a paper in a National and International conferences.

Dr. R. SRINEEVASAN is a Assistant Professor, PG \& Research Department of Physics, Government Arts College, Tiruvannamalai - 606 603, Tamilnadu, India. He has been completed a Minor project in UGC. $\mathrm{He}$ is guiding $2 \mathrm{Ph} . \mathrm{D}$., Research Scholars in the field of Materials Science and also more than $10 \mathrm{M}$. Phil., Students are passed out under his guidance. He published more than 15 research articles in a Peer reviewed journal and also he participated in a National and International conferences. He has 15 years of experience in the above field.

Mr. J. JOHNSON is a Ph.D., Research Scholar under the guidance of Dr. R. SRINEEVASAN M.Sc., M. Ed., M. Phil., Ph. D., in PG \& Research Department of Physics, Government Arts College, Tiruvannamalai - 606 603, Tamilnadu, India. $\mathrm{He}$ has completed M. Sc and

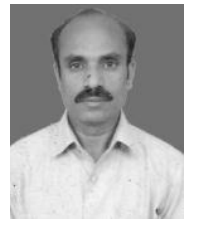
Peer reviewed journal and also he participated and presented a paper in a National and International conferences and also got a best reviewer award for his outstanding contribution in Journal of Physics and Chemistry of Solids. 